\title{
ANALISIS PERSEPSI KEMUDAHAN, SOCIAL INFLUENCE DAN PERSEPSI KEAMANAN TERHADAP MINAT PENGGUNAAN MARKETPLACE OLEH UMKM DI JABODETABEK
}

\author{
Novitasari \\ novitasari@akuntansi.pnj.ac.id \\ Mia Andika Sari \\ mia.andika@gmail.com
}

Program Studi Keuangan Dan Perbankan Politeknik Negeri Jakarta

\begin{abstract}
The fast growing of digital technology updates and development have created many technology platforms in the business field. Marketplace, is one of platform resulted from the online buying and selling market revolution which is now increasingly in demand by the public. This development have impacted on the increasing numbers of transactions for Indonesia market. The presence of a marketplace have expanding new business areas for business people or entrepreneurs, especially MSME's who uses the marketplace as a means of their digital marketing. By seeing this phenomena, it motivates the authors to analyze factors that influenced the use of marketplace by MSME's. This study aims to analyze the interest in the use of the marketplace by MSME's in Jabodetabek cities area based on their perceived ease of use, social influences and perceived of risk. It is hoped the results of this research can contribute to the digital economy business players, especially MSME's and able to provide suggestions for improvements to the policy makers and E-Commerce companies providing market. The object of this research is the owners of MSME's in Jabodetabek cities. The analysis technique is descriptive analysis. The results of the study can be described that the interest for using the marketplace by MSME's in Jabodetabek cities were influenced by the variables of perceived ease of use, social influence and perceived of risk. This can be seen from the responses, as many as $91.9 \%$ of MSME's actors/players responded that they were strongly agreed with to the perceived ease of use. As many as $80.75 \%$ of MSME's actors/players gave an agreed respond to the variable of social influence and as many as $88.2 \%$ of MSME's actors/players gave also an agreed respond to the perceived of risk.
\end{abstract}

Keywords: marketplace; interest in use; social influence; descriptive analysis; MSMEs

ABSTRAK

Pembaruan dan perkembangan teknologi digital yang begitu cepat dan cerdas banyak melahirkan platform di bidang bisnis. Marketplace, menjadi salah satu platform hasil dari revolusi pasar jual beli online yang sekarang ini semakin diminati oleh masyarakat. Perkembangan ini ditandai dengan jumlah transaksi di marketplace di Indonesia yang menunjukan data yang terus meningkat. Kehadiran marketplace memperluas lahan bisnis baru bagi para pelaku usaha, terutama UMKM yang memanfaatkan marketplace sebagai sarana digital marketing. Melihat fenomena tersebut, melatarbelakangi penulis untuk menganalisis faktor-faktor yang mempengaruhi penggunaan marketplace oleh UMKM. Penelitian ini bertujuan untuk menganalisa minat penggunaan marketplace oleh UMKM di Jabodetabek berdasarkan persepsi kemudahan, social influence dan persepsi keamanan. Diharapkan hasil penelitian ini dapat memberikan kontribusi bagi pelaku usaha ekonomi digital, khususnya UMKM dan mampu memberikan saran perbaikan untuk para pembuat kebijakan maupun perusahaan E-Commerce penyedia marketplace. Objek penelitian ini adalah para pemilik UMKM di Jabodetabek. Teknik analisis yang digunakan dengan menggunakan teknik analisis deskriptif. Hasil penelitian dapat dideskripsikan bahwa minat penggunaan marketplace oleh UMKM di Jabodetabek di pengaruhi oleh variabel persepsi kemudahan, social influence dan persepsi keamanan. Hal ini terlihat dari tanggapan responden, sebanyak 91,9\% pelaku UMKM memberikan tanggapan sangat setuju atas persepsi kemudahan, sebanyak 80,75\% pelaku UMKM memberikan tanggapan sangat setuju atas variabel social influence dan sebanyak 88,2\% pelaku UMKM memberikan tanggapan sangat setuju atas persepsi keamanan.

Kata Kunci: marketplace; minat penggunaan; social influence; analisis deskriptif; UMKM 


\section{PENDAHULUAN \\ Latar Belakang}

Perkembangan ekonomi digital di Indonesia terus melesat. Hal ini ditandai dengan pertumbuhan E-Commerce dan Marketplace yang menjamur. Di rilis dari laman situs Kementerian Komunikasi dan Informasi https://kominfo.go.id (skalanews, 2019), Indonesia merupakan negara 10 terbesar pertumbuhan e-commerce dengan pertumbuhan $78 \%$. Hal senada terlihat dari hasil survey Badan Pusat Statistik (Badan Pusat Statistik, 2019), yang menunjukkan bahwa selama tahun 2018 transaksi dari 13.485 usaha e-commerce sebanyak 24.821 .916 transaksi dengan nilai transaksi yang mencapai 17,21 triliun rupiah. Dan menurut data dari (Indonesian E-Commerce Association, 2020) atau IdEA, sampai dengan tahun 2020 jumlah marketplace yang terdaftar di IdEA ada sebanyak 68 marketplace.

Pada tahun 2018, e-commerce di Indonesia tercatat mengalami pertumbuhan yang sangat pesat dan diperkirakan akan terus meningkat seiring bertambahnya jumlah pengusaha dan pelaku Usaha Mikro Kecil dan Menengah (UMKM). Digitalisasi ekonomi ini ternyata menjadi peluang tersendiri untuk industri UMKM. Menurut data Kementerian Koperasi dan Usaha Kecil dan Menengah, Jumlah UMKM tahun 2018 ada sebanyak 64.194.057 unit, naik 2,02\% dari tahun 2017 (depkop.go.id, 2019).

\section{Ketertarikan UMKM untuk} menggunakan marketplace sebagai sarana memasarkan produknya disebabkan oleh banyak faktor, di antaranya adalah kondisi pasar offline yang semakin sulit dan sepi, pertumbuhan marketplace yang semakin beragam, marketplace memberikan kemudahan dan manfaat bagi UMKM, berjualan melalui marketplace lebih menghemat biaya, melihat usaha sejenis yang lebih maju setelah berjualaan melalui marketplace, dan konsumen lebih percaya untuk bertransaksi melalui marketplace. Beberapa penelitian terdahulu telah menganalisa beberapa faktor yang dapat mempengaruhi seseorang/pelaku usaha ekonomi ini ternyata menjadi peluang tersendiri untuk industri UMKM. Menurut data Kementerian Koperasi dan Usaha Kecil dan Menengah, Jumlah UMKM tahun 2018 ada sebanyak 64.194.057 unit, naik 2,02\% dari tahun 2017 (depkop.go.id, 2019).

Meski demikian, produk-produk yang dijual di platform marketplace oleh UMKM Indonesia masih di bawah $10 \%$, sehingga menjadi tantangan bersama agar membuat digital ekonomi dan dunia marketplace tidak hanya besar karena Indonesia sebatas sebagai market saja. Hal ini di dukung pula oleh keterangan dari Menteri Koperasi dan UKM Teten Masduki yang dilansir dari berita https://mnctrijaya.com (ANP, 2020), Teten Masduki mengatakan saat ini UMKM yang terhubung ke pasar online baru sekitar 13 persen atau 8 juta dari target 10 juta per tahun. Oleh karena itu, untuk menumbuhkan jumlah pelaku UMKM yang berselancar di dunia digital, Kemenkop UKM dan Kemkominfo bersama dengan para pelaku e-commerce menggagas program bertajuk 8 Juta UMKM Go Online (Kominfo, 2017).

Ketertarikan UMKM untuk menggunakan marketplace sebagai sarana memasarkan produknya disebabkan oleh banyak faktor, di antaranya adalah kondisi pasar offline yang semakin sulit dan sepi, pertumbuhan marketplace yang semakin beragam, marketplace memberikan kemudahan dan manfaat bagi UMKM, berjualan melalui marketplace lebih menghemat biaya, melihat usaha sejenis yang lebih maju setelah berjualaan melalui marketplace, dan konsumen lebih percaya untuk bertransaksi melalui marketplace. Beberapa penelitian terdahulu telah menganalisa beberapa faktor yang dapat mempengaruhi seseorang/pelaku usaha untuk menggunakan teknologi digital, diantaranya adalah hasil penelitian (Jati \& Laksito, 2012) menemukan bahwa faktor sosial berpengaruh signifikan positif terhadap minat pemanfaatan teknologi informasi digital. Dalam penelitian (Shomad \& Purnomosidhi, 2012) menjelaskan bahwa konstruk persepsi kegunaan, persepsi kemudahan berpengaruh positif terhadap minat menggunakan e-commerce. Sementara hasil penelitian (Winoorman, 2018) menyebutkan bahwa faktor persepsi kegunaan, persepsi kemudahan penggunaan, sikap dan norma subjektif berpengaruh terhadap penggunaan $e$ commerce dalam berwirausaha.

Kondisi ekonomi Indonesia yang mengalami resesi akibat Pandemi Covid- 
19, menyebabkan beberapa perusahaan besar dan UMKM terkena imbasnya. Pelaku usaha harus mengatur strategi agar dapat bertahan di tengah pandemi sekarang ini. Pertumbuhan marketplace yang semakin pesat menjadi salah satu celah bagi UMKM untuk bertahan. Semakin banyaknya platform marketplace hadir di Indonesia memberikan kemudahan pilihan bagi para UMKM untuk melakukan pemasaran atau penjualan online agar dapat menjangkau konsumen lebih luas lagi, tanpa ada batasan jarak.

Berdasarkan uraian di atas, menunjukkan bahwa banyak faktor yang menjadi penentu keputusan menggunakan marketplace oleh UMKM diantaranya faktor persepsi kemudahan, social influence (pengaruh dari lingkungan sekitar), dan persepsi keamanan. Meskipun demikian, hasil beberapa penelitian terdahulu, belum ditemukan adanya hasil yang konsisten mengenai faktor yang paling berpengaruh terhadap keputusan penggunaan marketplace oleh UMKM. Oleh karena itu, perlu melakukan penelitian lanjutan selain dikarenakan masih sedikitnya penelitian yang mengangkat tema minat penggunaan marketplace oleh UMKM.

\section{Permasalahan}

Berdasarkan fenomena masalah pada latar belakang tersebut, maka permasalahan pada penelitian ini adalah apakah faktor-faktor persepsi kemudahan, social influence, dan persepsi keamanan mempengaruhi minat penggunaan marketplace oleh UMKM di Jabodetabek.

\section{Tujuan}

Dengan demikian, penelitian ini bertujuan untuk menganalisis minat penggunaan marketplace oleh UMKM di Jabodetabek berdasarkan faktor persepsi kemudahan, Social influence, dan persepsi keamanan. Diharapkan hasil penelitian ini dapat memberikan kontribusi bagi pelaku usaha ekonomi digital, khususnya UMKM yang belum terjun dalam dunia marketplace dan mampu memberikan saran perbaikan untuk para pembuat kebijakan maupun pihak perusahaan penyedia marketplace dan pemerhati sistem e-commerce. Selain itu penelitian ini diharapkan juga dapat membuka jalan bagi peneliti selanjutnya untuk dapat menemukan masalah lain ataupun meneliti permasalahan yang sama dengan menganalisa faktor-faktor lain yang belum diteliti dan dengan metode penelitian yang berbeda.

\section{TINJAUAN PUSTAKA}

\section{Persepsi Kemudahan}

Davis dalam (Rahman \& Dewantara, 2017) mendefinisikan kemudahan penggunaan (ease of use) sebagai suatu tingkatan dimana seseorang percaya bahwa teknologi dapat dengan mudah dipahami. Konsep ini mencakup kejelasan tujuan penggunaan teknologi dan kemudahan penggunaan sistem sesuai dengan keinginan pemakai. Jika penggunaan situs ternyata lebih rumit dibandingkan manfaat yang diperoleh dari belanja online, maka penjual berpotensi akan lebih memilih melakukan pemasaran secara konvensional. Namun jika situs lebih mudah digunakan dan memberikan manfaat, penjual akan menggunakan situs tersebut untuk pemasaran online (Alwafi \& Magnadi, 2016).

Menurut (Romla \& Ratnawati, 2018), pembeli online percaya bahwa situs online shopping yang mudah pengoperasiannya, mudah dipahami, mudah dipelajari merupakan karakteristik kemudahan.

Berdasarkan penjelasan-penjelasan tersebut, maka indikator kemudahan yang dapat digunakan adalah mudah untuk diakses, mudah untuk dipelajari, mudah untuk digunakan, mudah memperoleh apa yang diinginkan pengguna, menarik perhatian pengguna dan mudah melakukan transaksi.

\section{Social Influence}

Menurut (Wang \& Chou, 2014), pengaruh sosial mengacu pada bagaimana orang lain mempengaruhi keputusan perilaku seseorang. Pengaruh sosial terkait dengan tekanan eksternal (dari orang-orang penting dalam hidup seseorang, seperti keluarga, teman, dan supervisor di tempat kerja). Pengaruh sosial adalah sejauh mana jaringan sosial mempengaruhi perilaku masyarakat melalui pesan dan sinyal dari orang lain yang memfasilitasi pembentukan nilai masyarakat yang dirasakan dari sistem teknologi.

(Wang \& Chou, 2014) menyatakan bahwa social influence dibentuk oleh dua dimensi, 
yaitu subjective norms dan visibility. Subjective norms, yaitu pengaruh sosial yang berhubungan dengan persepsi seseorang terhadap apa yang harus atau tidak boleh dilakukan. Sementara Visibility, yaitu pengaruh sosial yang terbentuk karena sebuah keadaan dari perilaku seseorang yang dapat diamati oleh orang lain, yang merefleksikan bahwa keputusan seseorang dipengaruhi oleh perilaku orang lain.

Berdasarkan definisi tersebut, maka indikator yang digunakan di dalam pengukuran variabel social influence adalah rasa yakin penjual, pengaruh dari lingkungan keluarga/ teman, melihat perilaku penjual lain, dan pengaruh dari teknologi.

\section{Persepsi Keamanan}

Chung dan Shin berpendapat (Chung \& Shin, 2010) bahwa keamanan bertransaksi dalam sistem belanja online menjadi faktor penting untuk menarik pelanggan, mengingat keamanan sebuah situs ritel yang akan berpengaruh pada kepuasan pelanggan. Keamanan sebagai kemampuan marketplace dalam melakukan pengontrolan dan penjagaan keamanan atas transaksi data.

Menurut Raman dan Annamalai (Raman \& Annamalai, 2011), Jaminan kemanan mengindikasikan bahwa pihak marketplace akan menjaga informasi pribadi konsumen, tidak akan dilihat, disimpan, dan dimanipulasi oleh pihak lain. Kerahasiaan melibatkan data yang hanya dapat dilihat oleh individu yang berwenang. Otentikasi memungkinkan suatu kegiatan tertentu hanya akan dilakukan setelah identifikasi, atau adanya jaminan bahwa identitas hanya digunakan untuk suatu urusan tertentu saja (misalnya situs web).

Dari penjelasan tersebut dapat disimpulkan, indikator keamanan yang dapat digunakan yaitu marketplace memiliki sistem keamanan yang baik bagi merchant, marketplace memiliki sistem keamanan yang baik bagi konsumen, marketplace mammpu menjaga data diri merchant, marketplace mampu menyelesaikan masalah transaksi.

\section{Minat Penggunaan}

Minat penggunaan dapat didefinisikan sebagi minat perilaku seseorang untuk menggunakan sesuatu. Minat perilaku menurut Jogiyanto (Jogiyanto, 2007) adalah suatu keinginan (minat) seseorang untuk melakukan suatu perilaku tertentu. Indikator yang dapat digunakan untuk mengukur minat penggunaan adalah keinginan menggunakan sistem, keinginan mengerjakan pekerjaan menggunakan sistem, dan keinginan menggunakan sistem secara sering.

\section{METODE PENELITIAN}

Penelitian ini merupakan penelitian asosiatif, yaitu penelitian yang bertujuan mengetahui hubungan antara dua variabel atau lebih (Sugiyono, 2017). Operasionalisasi variabel dalam penelitian ini dapat dijabarkan dalam tabel berikut:

Tabel 1 Operasionalisasi Variabel

\begin{tabular}{|c|c|c|}
\hline No & $\begin{array}{l}\text { Variabel } \\
\text { Penelitian }\end{array}$ & Indikator \\
\hline 1 & $\begin{array}{l}\text { Persepsi } \\
\text { Kemudahan }\end{array}$ & $\begin{array}{l}\text { - mudah untuk diakses, } \\
\text { - mudah untuk } \\
\text { dipelajari, } \\
\text { - mudah } \\
\text { digunakan, } \\
\text { - mudah memperoleh } \\
\text { apa yang diinginkan } \\
\text { pengguna, } \\
\text { - menarik perhatian } \\
\text { pengguna dan } \\
\text { - mudah melakukan } \\
\text { transaksi. }\end{array}$ \\
\hline 2 & $\begin{array}{l}\text { Social } \\
\text { Influence }\end{array}$ & $\begin{array}{l}\text { - } \text { rasa yakin penjual, } \\
\text { - pengaruh dari } \\
\text { lingkungan keluarga/ } \\
\text { teman, } \\
\text { - melihat perilaku } \\
\text { penjual lain, dan } \\
\text { - pengaruh dari } \\
\text { teknologi. }\end{array}$ \\
\hline 3 & $\begin{array}{l}\text { Persepsi } \\
\text { Keamanan }\end{array}$ & $\begin{array}{l}\text { - marketplace memiliki } \\
\text { sistem keamanan } \\
\text { yang baik bagi } \\
\text { merchant, } \\
\text { - marketplace memiliki } \\
\text { sistem keamanan } \\
\text { yang baik bagi } \\
\text { konsumen, } \\
\text { - marketplace mammpu } \\
\text { menjaga data diri } \\
\text { merchant, }\end{array}$ \\
\hline
\end{tabular}




\begin{tabular}{|c|c|c|}
\hline & & $\begin{array}{l}\text { - marketplace mampu } \\
\text { menyelesaikan } \\
\text { masalah transaksi }\end{array}$ \\
\hline 4 & $\begin{array}{l}\text { Minat } \\
\text { Penggunaan }\end{array}$ & $\begin{array}{l}\text { - keinginan } \\
\text { menggunakan sistem } \\
\text { - keinginan } \\
\text { mengerjakan } \\
\text { pekerjaan } \\
\text { menggunakan sistem } \\
\text { - keinginan } \\
\text { menggunakan sistem } \\
\text { secara sering }\end{array}$ \\
\hline
\end{tabular}

Sumber; Data Primer

Metode pengumpulan data pada penelitian ini dengan memanfaatkan data primer yang diperoleh langsung dari responden berupa respon UMKM dalam menilai faktor-faktor yang menjadi pertimbangan menggunakan Marketplace. Pengumpulan data dilakukan dengan menyebarkan angket (Kuesioner) pada UMKM dari berbagai jenis usaha, mulai dari usaha fashion, kuliner, kosmetik, kerajinan tangan dan lain-lain.

Sebelum penyebaran kuesioner kepada UMKM yang lebih luas, instrumen kuesioner terlebih dahulu diuji validitas dan reliabilitasnya, dengan menggunakan 46 UMKM yang tidak disertakan dalam analisa data. Uji validitas dilakukan dengan menggunakan rumus korelasi Pearson, yang diolah dengan software Statistical Program for Society Science (SPSS) V.25. Sebuah indikator dikatakan valid jika mempunyai nilai koefisien korelasi ( $r$ ) hitung lebih besar dari r-tabel. Sementara untuk uji reliabilitas, indikator dinyatakan reliabel jika memiliki nilai Cronbach Alpha > 0,60 (Sujarweni, 2014) atau memiliki $r$ - hitung $>r$-tabel.

Obyek penelitian di fokuskan pada pengumpulan informasi atau respon Pelaku UMKM mengenai faktor yang menjadi pertimbangan bagi para UMKM untuk menggunakan marketplace sebagai sarana pemasaran digital (online).

Dalam kaitannya dengan fokus penelitian yang penulis pilih maka populasi dalam penelitian ini adalah para pelaku UMKM di Jabodetabek dari berbagai jenis bidang usaha, seperti kuliner, fashion, kosmetik, dan lain sebagainya. Teknik sampling yang di gunakan dalam penelitian ini menggunakan teknik Purposive Sampling, dimana pengambilan sampel dilakukan dengan tujuan tertentu. Sampel yang diambil sebanyak 100 sampel dengan kiteria berdomisili di wilayah Jakarta, Bogor, Depok, Tangerang dan Bekasi dan menggunakan marketplace sebaga sarana marketing digital.

Dalam penelitian ini teknik analisis yang digunakan teknik analisis deskriptif, yaitu dilakukan dengan langkah-langkah mengumpulkan data, mengklasifikasikan data, pemberian bobot, menghitung skor dan persentase, memberikan interpretasi atas tabel distribusi frekuensi dan menarik kesimpulan (Sugiyono, 2017).

\section{HASIL DAN PEMBAHASAN}

\section{Uji Validitas Dan Reliabilitas}

Sebelum sebuah kuesioner disebarluaskan, item pernyataan dalam kuesioner harus terlebih dahulu diujicobakan untuk melihat apakah item pernyataan kuesioner sudah memenuhi validitas dan reliabilitas atau belum. Dalam penelitian ini, dengan jumlah sampel uji coba sebanyak 46 responden dilakukan uji validitas dan reliablitas dengan hasil sebagai berikut :

Tabel 2 Hasil Uji Validitas

\begin{tabular}{|c|c|c|}
\hline $\begin{array}{l}\text { Item } \\
\text { Pernyataan }\end{array}$ & r hitung & $\begin{array}{l}\text { Hasil } \\
\text { Pengolahan } \\
\text { Data } \\
\end{array}$ \\
\hline X1.1 & 0.717 & Valid \\
\hline $\mathrm{X} 1.2$ & 0.565 & Valid \\
\hline X1.3 & 0.803 & Valid \\
\hline $\mathrm{X} 1.4$ & 0.724 & Valid \\
\hline$X 1.5$ & 0.817 & Valid \\
\hline X1.6 & 0.764 & Valid \\
\hline $\mathrm{X} 2.1$ & 0.844 & Valid \\
\hline $\mathrm{X} 2.2$ & 0.856 & Valid \\
\hline $\mathrm{X} 2.3$ & 0.437 & Valid \\
\hline $\mathrm{X} 2.4$ & 0.815 & Valid \\
\hline X3.1 & 0.837 & Valid \\
\hline $\mathrm{X} 3.2$ & 0.86 & Valid \\
\hline X3.3 & 0.888 & Valid \\
\hline X3.4 & 0.817 & Valid \\
\hline Y1.1 & 0.402 & Valid \\
\hline Y1.2 & 0.724 & Valid \\
\hline Y1.3 & 0.609 & Valid \\
\hline Y1.4 & 0.556 & Valid \\
\hline Y1.5 & 0.502 & Valid \\
\hline Y1.6 & 0.659 & Valid \\
\hline Y1.7 & 0.64 & Valid \\
\hline Y1.8 & 0.632 & Valid \\
\hline
\end{tabular}

Sumber : data diolah, 2020

Dengan jumlah sampel 46 responden dan tingkat kesalahan 5\%, diketahui nilai $\mathrm{r}$ tabel 
sebesar 0,291. Dalam Tabel 2 hasil uji validitas didapatkan hasil bahwa dari semua item pernyataan variabel yang diteliti memiliki nilai r-hitung > r-tabel, sehingga semua item pernyataan untuk variabel persepsi kemudahan, social influence, persepsi keamanan dan minat penggunaan dalam kuesioner dinyatakan valid. Sementara untuk hasil uji reliabilitas dapat dilihat dalam tabel berikut :

Untuk hasil uji reliabilitas pada Tabel 3, variabel persepsi kemudahan, social influence, persepsi keamanan dan minat penggunaan yang diteliti memiliki nilai Cronbach Alpha >0,60, sehingga semua variabel dinyatakan reliabel atau konstan.

Tabel 3 Hasil Uji Reliabilitas

\begin{tabular}{cc} 
Variabel & Cronbach'Alpha \\
\hline \hline X1 & 0.819 \\
X2 & 0.751 \\
X3 & 0.868 \\
Y & 0.718 \\
\hline
\end{tabular}

Sumber : data diolah, 2020

Setelah semua variabel dan item pernyataan dalam kuesioner dinyatakan valid dan reliabel, maka selanjutnya adalah menyebarkan kuesioner pada sampel yang lebih luas.

\section{Tabulasi Data}

Dari hasil proses tabulasi data dan pemilihan data, sampel akhir yang terkumpul ada sebanyak 100 responden dengan karakteristik sebagai berikut :

Tabel 4 Identitas Responden

\begin{tabular}{rlrr}
\hline \hline No & Domisili & $\begin{array}{l}\text { Jumlah } \\
\text { Responden }\end{array}$ & Persentase \\
\hline \hline 1 & Jakaha & 38 & $38 \%$ \\
2 & Bogor & 5 & $5 \%$ \\
3 & Depok & 17 & $17 \%$ \\
4 & Tangerang & 17 & $17 \%$ \\
5 & Bekasi & 23 & $23 \%$ \\
\hline \hline
\end{tabular}

Sumber : data diolah, 2020

Dari Tabel 4 menunjukkan bahwa sebanyak 38 responden berdomisili di Jakarta, sebanyak 5 responden berdomisili di Bogor, sebanyak 17 responden berdomisili di Depok, sebanyak 17 responden berdomisili di Tangerang, dan sebanyak 23 responden berdomisili di Bekasi. Dari data tersebut dapat disimpulkan bahwa pengguna platform marketplace didominasi usaha dari Jakarta.
Tabel 5 Pilihan Marketplace Yang

Digunakan

\begin{tabular}{clcr}
\hline \hline No & Marketplace & $\begin{array}{c}\text { Jumlah } \\
\text { Responden }\end{array}$ & Persentase \\
\hline \hline 1 & Blibli & 1 & $1 \%$ \\
2 & Bukalapak & 4 & $4 \%$ \\
3 & Shopee & 42 & $42 \%$ \\
4 & Tokopedia & 49 & $49 \%$ \\
5 & Grab Food & 1 & $1 \%$ \\
6 & OLX & 1 & $1 \%$ \\
7 & Lazada & 2 & $2 \%$ \\
\hline \hline
\end{tabular}

Sumber : data diolah, 2020

Pada Tabel 5 dapat dilihat bahwa mayoritas responden menggunakan platform marketplace Tokopedia sebagai sarana berjualan yaitu sebanyak 49 orang (49\%). Yang disusul oleh Shopee di urutan kedua sebagai platform marketplace terbanyak yang responden gunakan yaitu sebanyak 42 orang (42\%).

Tabel 6 Lama Penggunaan Marketplace Oleh UMKM

Sumber, data diolah, 2020

Dari Tabel 6 dapat dilihat bahwa sebanyak 19 responden (19\%) telah menggunakan platform marketplace selama kurang dari 3 bulan, sebanyak 26 responden (26\%) telah

\begin{tabular}{llll}
\hline \hline No & $\begin{array}{l}\text { Lama } \\
\text { Penggunaan }\end{array}$ & $\begin{array}{l}\text { Jumlah } \\
\text { Responden }\end{array}$ & Persentase \\
\hline \hline 1 & $<3$ Bulan & 19 & $19 \%$ \\
2 & 3 - 6 Bulan & 26 & $26 \%$ \\
3 & 6 - 12 Bulan & 19 & $19 \%$ \\
4 & $>1$ Tahun & 36 & $36 \%$ \\
\hline \hline
\end{tabular}

menggunakan platform marketplace selama 3 sampai 6 bulan, sebanyak 19 responden (19\%) telah menggunakan platform marketplace selama 6 sampai 12 bulan, dan sebanyak 36 responden $(36 \%)$ telah menggunakan platform marketplace selama lebih dari satu tahun.

\section{Tabel 7 Jenis Usaha UMKM}

Sumber, data diolah, 2020

Berdasarkan hasil pengumpulan data kuesioner yang dirangkum dalam Tabel 7, diketahui jenis usaha UMKM yang ada di 


\begin{tabular}{|c|c|c|c|}
\hline No. & Jenis Usaha & Jumlah & Persentase \\
\hline 1 & Fashion & 40 & $40 \%$ \\
\hline 2 & Kuliner & 22 & $22 \%$ \\
\hline 6 & Kosmetik & 10 & $10 \%$ \\
\hline 3 & Sembako & 4 & $4 \%$ \\
\hline 5 & Merchandise & 4 & $4 \%$ \\
\hline 8 & $\begin{array}{l}\text { Jasa } \\
\text { Kerajinan }\end{array}$ & 4 & $4 \%$ \\
\hline 7 & $\begin{array}{l}\text { Tangan } \\
\text { Perlengkapan }\end{array}$ & 3 & $3 \%$ \\
\hline 9 & $\begin{array}{l}\text { otomotif } \\
\text { Perlengkapan }\end{array}$ & 3 & $3 \%$ \\
\hline 10 & Rumah Tangga & 2 & $2 \%$ \\
\hline 11 & Tanaman & 2 & $2 \%$ \\
\hline 12 & Lain-Lain & 6 & $6 \%$ \\
\hline
\end{tabular}

Berdasarkan Tabel 9 diketahui untuk kriteria tanggapan Sangat Setuju diberikan bobot 5, kriteria tanggapan Setuju diberikan bobot 4, kriteria tanggapan Ragu-ragu diberikan bobot 3, kriteria tanggapan Tidak Setuju diberi bobot 2 dan kriteria tanggapan Sangat Tidak Setuju diberikan bobot 1 .

\section{Interval Skor}

Setelah kriteria tanggapan diberikan bobot, maka tahap berikutnya yaitu menentukan interval skor untuk mengelompokkan penilaian kriteria tanggapan dengan cara membuat range/batas atas dan batas bawah untuk setiap kriteria tanggapan berdasarkan skor maksimum dan skor minimum.

marketplace di dominasi oleh UMKM yang menjual barang fashion seperti baju, celana, sepatu dengan persentase sebesar $40 \%$, lalu di ikuti oleh UMKM yang memiliki usaha kuliner (menjual makanan olahan) sebesar 22\%, yang menjual kosmetik sebesar $10 \%$, dan terakhir ada jenis usaha lain-lain sebesar $6 \%$.

\section{Klasifikasi Data}

Tahap analisis selanjutnya setelah data terkumpul yaitu mengklasifikasikan data berdasarkan jenis jawaban yang diperoleh. Dari hasil penyebaran kuesioner, diperoleh data 100 responden dengan klasifikasi jawaban ada di tabel 8 .

Berdasarkan Tabel 8 diketahui bahwa untuk variabel persepsi kemudahan di dominasi oleh tanggapan Sangat Setuju, begitu pula untuk variable social influence dan persepsi keamanan, tanggapan dari responden banyak di dominasi oleh kriteria tanggapan Sangat Setuju.

\section{Pembobotan Kriteria}

Setelah data diklasifikasi, maka langkah analisis selanjutnya adalah memberikan bobot untuk masing-masing kriteria tanggapan.

\begin{tabular}{clc}
\multicolumn{2}{c}{ Tabel 9 Bobot Kriteria Tanggapan } \\
Kriteria \\
No & Tanggapan & Bobot \\
\hline \hline 1 & Sangat Setuju & 5 \\
2 & Setuju & 4 \\
3 & Ragu-Ragu & 3 \\
4 & Tidak Setuju & 2 \\
5 & Sangat Tidak & 1 \\
\hline \hline
\end{tabular}

Sumber : data diolah, 2020

\section{Penghitungan Skor Tiap Variabel \\ Tahap analisis selanjutnya yaitu} menghitung skor untuk masing-masing item pernyataan dengan cara mengkalikan frekuensi tanggapan dengan bobot kriteria tanggapan, menjumlahkan semua skor item pernyataan dari setiap variabel, menghitung rata-rata skor variabel dan menghitung persentase dengan cara membagi skor rata-rata variabel dengan skor maksimum. Hasilnya tersaji dalam tabel distribusi frekuensi, lihat tabel 11.

Berdasarkan tabel distribusi frekuensi tersebut dapat disimpulkan untuk variabel persepsi kemudahan memiliki skor rata-rata sebesar 459,5 atau dari 100 orang responden sebanyak 91,9\% memberi tanggapan Sangat Setuju jika variabel persepsi kemudahan mempengaruhi minat penggunaan marketplace oleh UMKM di Jabodetabek.

Sementara jika dilihat dari item pernyataan, tanggapan responden atas pernyataan Item No,1 (Situs marketplace yang digunakan saat ini untuk berjualan mudah untuk diakses) dari 100 orang responden, sebanyak 75 responden menyatakan Sangat Setuju dengan skor item sebesar 474. 
Untuk item pernyataan No.2 (Situs marketplace yang digunakan saat ini untuk berjualan mudah untuk dipelajari ) 68 responden menyatakan sangat setuju, dengan skor item 466.

Item pernyataan No.3 (Situs marketplace yang digunakan saat ini untuk berjualan mudah untuk digunakan ) dari 100 responden, sebanyak 75 orang menyatakan sangat setuju.

Item pernyataan No.4 (Fitur-fitir yang ada di marketplace yang saya gunakan sekarang sudah sesuai dnegan kebutuhan saya) sebanyak 64 orang menyatakan sangat setuju dengan skor item 458 .

Untuk item pernyataan No.5 (Menurut saya tampilan situs marketplace yang saya gunakan saat ini menarik konsumen) sebanyak 56 orang responden menyatakan sangat setuju dengan skor item 443.

Sebanyak 56 orang responden juga menyatakan sangat setuju terhadap item pernyataan No. 6 (Tata letak menu di situs marketplace sudah tertata dengan baik).

Berdasarkan hasil penjelasan tersebut, dapat disimpulkan bahwa indikator situs marketplace yang mudah diakses menjadi faktor yang mempengaruhi minat UMKM untuk menggunakan marketplace.

Untuk variabel social influence memiliki hasil distribusi frekuensi ada di tabel 12.

Dari Tabel 12 dapat disimpulkan untuk variabel social influence memiliki skor rata-rata sebesar 403,75 atau dari 100 orang responden sebanyak 80,75\% memberi tanggapan Sangat Setuju jika variabel social influence mempengaruhi minat penggunaan marketplace oleh UMKM di Jabodetabek.

Sementara jika dilihat dari item pernyataan, tanggapan responden atas pernyataan Item No,1 (Saya mengetahu marketplace untuk sarana berjualan dari karyawan/teman/keluarga/rekan bisnis) dari 100 orang responden, sebanyak 46 responden menyatakan Sangat Setuju dengan skor item sebesar 386.

Untuk item pernyataan No.2 (Saya menggunakan marketplace untuk sarana berjualan atas referensi dari teman/keluarga ) 37 responden menyatakan sangat setuju, dengan skor item 362 .

Item pernyataan No.3 (Saya tertarik menggunakan marketplace karena melihat usaha lain mampu meningkatkan penjualannya) dari 100 responden, sebanyak 75 orang menyatakan sangat setuju dengan skor item
470. Item pernyataan No.4 (Saya tertarik menggunakan marketplace karena iklan) sebanyak 48 orang menyatakan sangat setuju dengan skor item 397.

Dari hasil uraian analisa tersebut, dapat dijelaskan bahwa indikator melihat perilaku orang lain yang mampu meningkatkan penjualannya melalui marketplace menjadi indikator yang paling berpengaruh bagi UMKM dalam menggunakan marketplace juga.

Sementara untuk hasil distribusi frekuensi variabel persepsi keamanan dapat di lihat pada tabel 13.

Berdasarkan Tabel 13 distribusi frekuensi dapat disimpulkan untuk variabel persepsi keamanan memiliki skor rata-rata sebesar 441 atau dari 100 orang responden sebanyak $88,2 \%$ memberi tanggapan Sangat Setuju jika variabel persepsi keamanan mempengaruhi minat penggunaan marketplace oleh UMKM di Jabodetabek.

Sementara jika dilihat dari item pernyataan, tanggapan responden atas pernyataan Item No,1 (Saya meyakini marketplace yang saya gunakan saat ini memiliki sistem keamanan yang baik bagi usaha saya) dari 100 orang responden, sebanyak 50 responden menyatakan Sangat Setuju dengan skor item sebesar 438.

Untuk item pernyataan No.2 (Saya meyakini marketplace yang saya gunakan saat ini memiliki sistem keamanan yang baik bagi transaksi konsumen dan calon konsumen saya ) 56 responden menyatakan sangat setuju, dengan skor item 446.

Item pernyataan No.3 (Saya meyakini bahwa sistem keamanan marketplace yang saya gunakan saat ini mampu menjaga data diri saya sebagai merchant) dari 100 responden, sebanyak 54 orang menyatakan sangat setuju dengan skor item 437.

Item pernyataan No.4 (Saya meyakini bahwa sistem keamanan marketplace yang saya gunakan saat ini mampu menyelesaikan masalah transaksi saya) sebanyak 55 orang menyatakan sangat setuju dengan skor item 443.

Berdasarkan hasil analisa tersebut, dapat disimpulkan bahwa menurut penilaian UMKM, marketplace yang memiliki sistem keamanan yang baik bagi transaksi konsumen dan calon konsumen serta marketplace yang dapat menyelesaikan masalah transaksi merchant dengan konsumen menjadi faktor yang paling 
mempengaruhi minat UMKM untuk menggunakan marketplace.

\section{KESIMPULAN}

Berdasarkan hasil analisis data, maka dapat diambil kesimpulan bahwa variabel persepsi kemudahan, social influence dan persepsi keamanan dapat menjadi faktor yang mempengaruhi minat UMKM di Jabodetabek untuk menggunakan marketplace, yaitu dengan persentase sebesar $91,9 \%, 80,75 \%$ dan $88,2 \%$ responden memberikan tanggapan Sangat Setuju. Indikatornya adalah para pelaku UMKM percaya jika marketplace yang mereka gunakan mudah diakses, dapat membantu UMKM meningkatkan omzet penjualannya dan dapat mengatasi permasalahan transaksi antara UMKM dengan konsumen.

Saran yang dapat penulis berikan untuk UMKM yang belum terjun dalam digital marketing melalui marketplace ini adalah hendaknya UMKM segera membuat akun toko mereka di marketplace yang memiliki kredibilitas dan tingkat kunjungan tertinggi agar dapat membantu meningkatkan omzet penjualan UMKM apalagi ditengah pandemi seperti sekarang ini. Sementara untuk UMKM yang sudah menggunakan marketplace, hendaknya dapat lebih aktif lagi memasarkan produknya sehingga dapat menjadi star seller/top seller. Untuk para pembuat kebijakan dan perusahaan platform marketplace serta pemerhati sistem e-commerce, sebaiknya tidak mempersulit aturan dalam jual beli online, memperhatikan kembali faktor kemudahan, dan faktor keamanan dalam penerapan sistem transaksi e-commerce. serta dapat memberikan pelatihan teknologi digital bagi para pelaku UMKM, agar lebih banyak lagi UMKM yang go online.

Penelitian ini memiliki banyak keterbatasan, sehingga dapat menjadi celah bagi peneliti selanjutnya untuk dapat meneliti tema lain yang berkaitan dengan efektivitas marketplace dalam meningkatkan omzet penjualan, dengan UMKM yang lebih spesifik (misalnya studi kasus pada UKM Fashion) dengan teknik analisis yang berbeda dari penelitian ini.

\section{DAFTAR PUSTAKA}

Alwafi, F., dan Magnadi R. H. (2016). Pengaruh Persepsi Keamanan, Kemudahan, Bertransaksi, Kepercayaan
Terhadap Toko dan Pengalaman Berbelanja Terhadap Minat Beli Secara Online Pada Situs Jual Beli Tokopedia.com. Diponogoro Journal of Management. Volume 5, Nomor 2, Hal: 115

ANP. (2020). PEMERINTAH BERHARAP MAHASISWA BANTU UMKM TERHUBUNG KE MARKETPLACE ONLINE. Mnctrijaya.Com. https://mnctrijaya.com/news/detail/34323 /pemerintah-berharap-mahasiswa-bantuumkm-terhubung-ke-marketplace-online

Badan Pusat Statistik. (2019). Statistik ECommerce 2019. Www.Bps.Go.Id. https://www.bps.go.id/publication/2019/1 2/18/fd1e96b05342e479a83917c6/statisti k-e-commerce-2019.html

Chung, K., \& Shin, J. (2010). The antecedents and consequents of relationship quality in internet shopping. Asia Pacific Journal of Marketing and Logistics.

depkop.go.id. (2019). PERKEMBANGAN DATA USAHA MIKRO, KECIL, MENENGAH (UMKM) DAN USAHA BESAR (UB). Depkop.Go.Id. http://www.depkop.go.id/uploads/laporan /1580223129_PERKEMBANGAN DATA USAHA MIKRO, KECIL, MENENGAH (UMKM) DAN USAHA BESAR (UB) TAHUN 2017 - 2018.pdf

Indonesian E-Commerce Association. (2020). direktori member. Www.Idea.or.Id. https://www.idea.or.id/direktori-member

Jati, N. J., \& Laksito, H. (2012). Analisis faktorfaktor yang mempengaruhi minat pemanfaatan dan penggunaan sistem eticket (Studi empiris pada biro perjalanan di Kota Semarang). Fakultas Ekonomika dan Bisnis.

Jogiyanto, J. (2007). Sistem Informasi Keperilakuan (Revisi). Yogyakarta: Andi Offset.

Kominfo, B. H. (2017). GO DIGITAL! Gerakan Nasional UMKM Go Online. Kominfo.Go.Id.

https://www.kominfo.go.id/content/detail /11346/siaran-pers-no-

216hmkominfo112017-tentang-godigital-gerakan-nasional-umkm-goonline/0/siaran_pers

Rahman, A., \& Dewantara, R. Y. (2017). Pengaruh Kemudahan Penggunaan dan Kemanfaatan Teknologi Informasi terhadap Minat Menggunakan Situs Jual 
Beli Online"(Studi Kasus pada Pengguna Situs Jual Beli “Z”). Jurnal Administrasi Bisnis, 52(1), 1-7.

Raman, A., \& Annamalai, V. (2011). Web services and e-shopping decisions: A study on malaysian e-consumer. Wireless Information Networks \& Business Information System, 2(5), 54-60.

Romla, S., \& Ratnawati, A. (2018). Keputusan Pembelian E-Commerce Melalui Kemudahan Penggunaan, Kualitas Informasi Dan Kualitas Interaksi Layanan Web. Jurnal Ekonomi Dan Bisnis, 19(1), 59-70.

Shomad, A. C., \& Purnomosidhi, B. (2012). Pengaruh kepercayaan, persepsi kegunaan, persepsi kemudahan, dan persepsi risiko terhadap perilaku penggunaan E-commerce. Jurnal Ilmiah Mahasiswa FEB, 1(2).

skalanews. (2019). Kemkominfo: Pertumbuhan e-Commerce Indonesia Capai 78 Persen. Kominfo.Go.Id.

https://kominfo.go.id/content/detail/1677 0/kemkominfo-pertumbuhan-ecommerce-indonesia-capai-78persen/0/sorotan_media

Sugiyono, P. D. (2017). Metode Penelitian Bisnis: Pendekatan Kuantitatif, Kualitatif, Kombinasi, dan R\&D. Penerbit $C V$. Alfabeta: Bandung.

Sujarweni, W. (2014). SPSS Untuk Penelitian Cet I. Yogyakarta. Pustaka Baru Press.

Wang, E. S.-T., \& Chou, N. P.-Y. (2014). Consumer characteristics, social influence, and system factors on online group-buying repurchasing intention. Journal of Electronic Commerce Research, 15(2), 119.

Winoorman, M. P. (2018). FAKTORFAKTOR YANG MEMPENGARUHI MAHASISWA DALAM BERWIRAUSAHA MENGGUNAKAN E-COMMERCE DI YOGYAKARTA. In dspace.uii.ac.id. Universitas Islam Indonesia.

\section{DAFTAR TABEL}


Tabel 8 Klasifikasi Data

\begin{tabular}{|c|c|c|c|c|c|c|c|c|c|c|c|c|c|c|c|}
\hline \multirow{2}{*}{ No } & \multirow{2}{*}{$\begin{array}{l}\text { Kriteria } \\
\text { Tanggapan } \\
\end{array}$} & \multicolumn{4}{|c|}{ Persepsi Kemudahan (X1) } & \multicolumn{6}{|c|}{ Social Influence (X2) } & \multicolumn{4}{|c|}{ Persepsi Keamanan (X3) } \\
\hline & & X1.1 & $\mathrm{X} 1.2$ & $\mathrm{X} 1.3$ & X1.4 & X1.5 & X1.6 & X2.1 & $\mathrm{X} 2.2$ & X2.3 & X2.4 & X3.1 & X3.2 & X3.3 & X3.4 \\
\hline & Sangat & & & & & & & & & & & & & & \\
\hline 1 & Setuju & 75 & 68 & 75 & 64 & 56 & 56 & 46 & 37 & 75 & 48 & 50 & 56 & 54 & 55 \\
\hline 2 & Setuju & 24 & 30 & 22 & 30 & 34 & 32 & 21 & 24 & 20 & 22 & 39 & 35 & 32 & 35 \\
\hline 3 & $\begin{array}{l}\text { Ragu-ragu } \\
\text { Tidak }\end{array}$ & 1 & 2 & 3 & 6 & 7 & 12 & 15 & 15 & 5 & 15 & 10 & 8 & 12 & 9 \\
\hline 4 & $\begin{array}{l}\text { Setuju } \\
\text { Sangat } \\
\text { Tidak }\end{array}$ & 0 & 0 & 0 & 0 & 3 & 0 & 9 & 12 & 0 & 9 & 1 & 1 & 1 & 0 \\
\hline 5 & Setuju & 0 & 0 & 0 & 0 & 0 & 0 & 9 & 12 & 0 & 6 & 0 & 0 & 1 & 1 \\
\hline
\end{tabular}

Sumber : data diolah, 2020

Tabel 11 Distribusi Frekuensi Tanggapan Responden Terhadap Variabel Persepsi Kemudahan

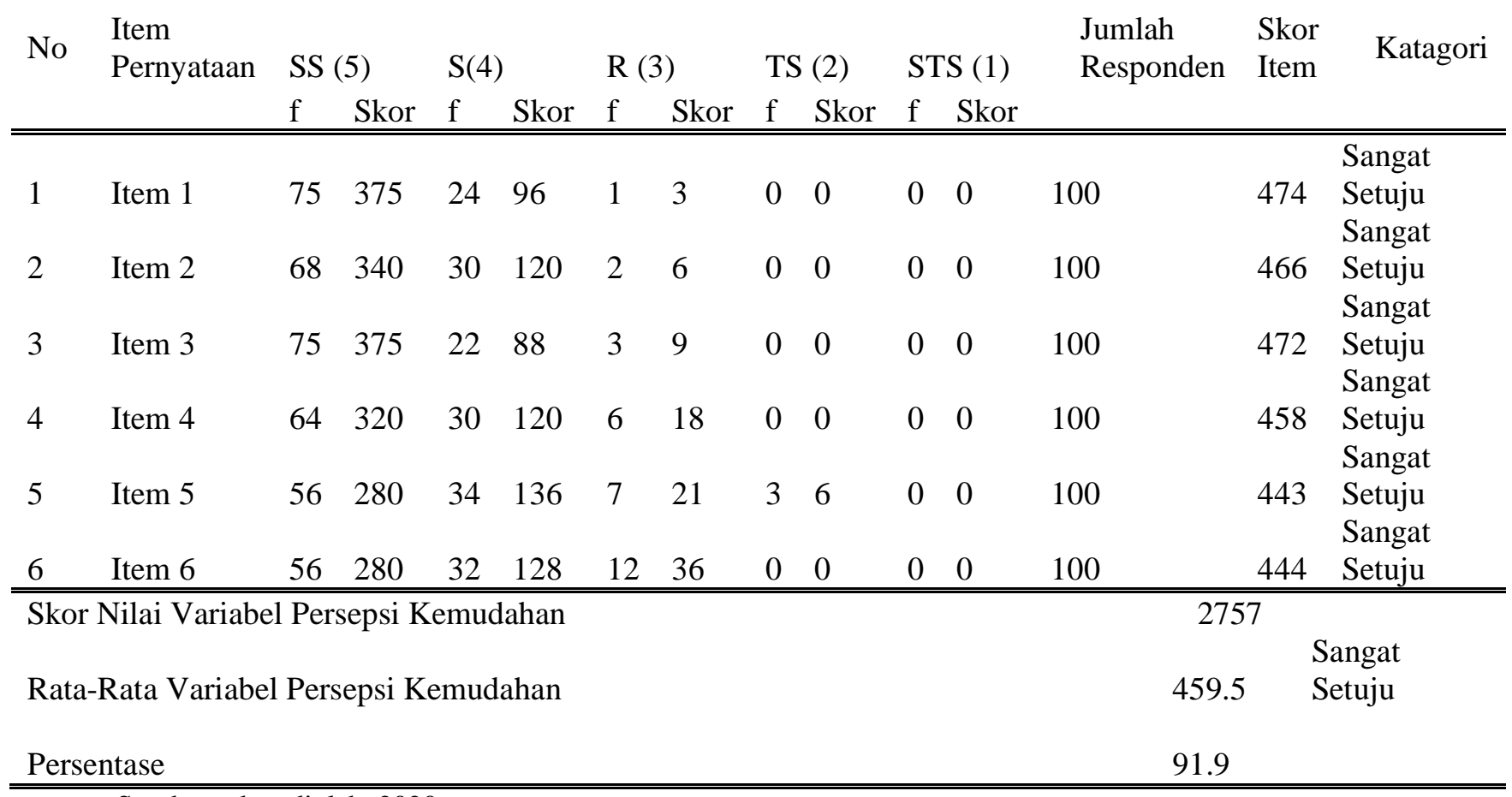

Sumber : data diolah, 2020

Tabel 12 Distribusi Frekuensi Tanggapan Responden Terhadap Variabel Social Influence

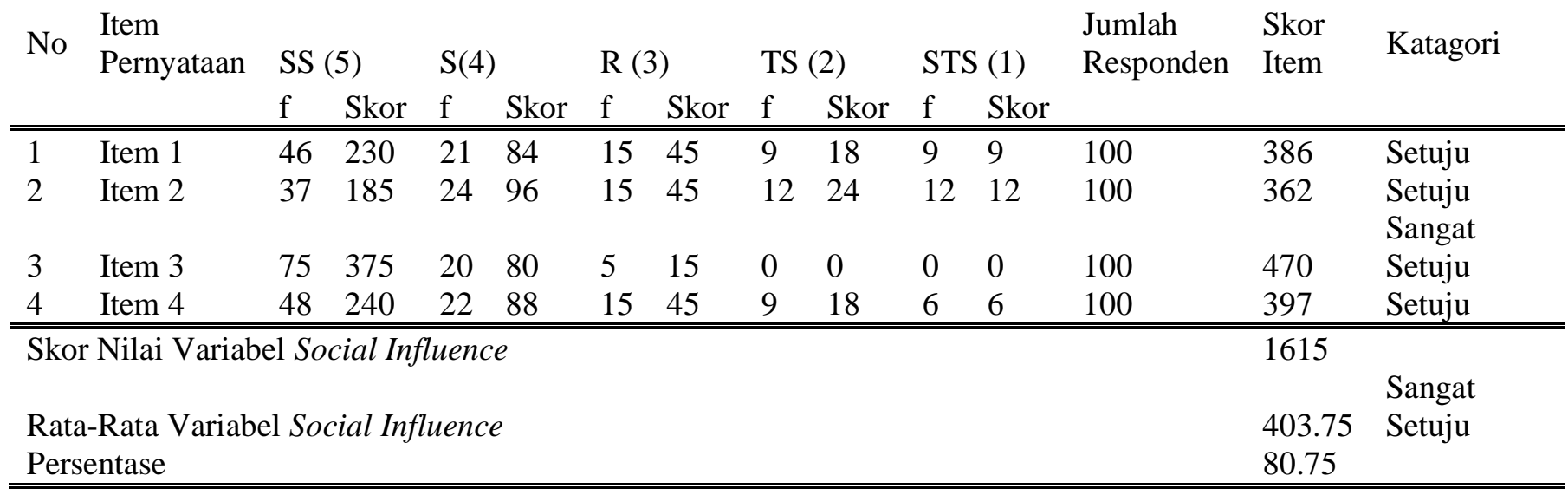

Sumber : data diolah, 2020 
Tabel 13 Distribusi Frekuensi Tanggapan Responden Terhadap Variabel Persepsi Keamanan

\begin{tabular}{|c|c|c|c|c|c|c|c|c|c|c|c|c|c|c|}
\hline \multirow[t]{2}{*}{ No } & \multirow[t]{2}{*}{$\begin{array}{l}\text { Item } \\
\text { Pernyataan }\end{array}$} & \multicolumn{2}{|c|}{ SS (5) } & \multicolumn{2}{|c|}{$\mathrm{S}(4)$} & \multicolumn{2}{|c|}{$\mathrm{R}(3)$} & \multicolumn{2}{|c|}{ TS (2) } & \multicolumn{2}{|c|}{ STS (1) } & \multirow[t]{2}{*}{$\begin{array}{l}\text { Jumlah } \\
\text { Responden }\end{array}$} & \multirow[t]{2}{*}{$\begin{array}{l}\text { Skor } \\
\text { Item }\end{array}$} & \multirow[t]{2}{*}{ Katagori } \\
\hline & & $\mathrm{f}$ & Skor & $\mathrm{f}$ & Skor & $\mathrm{f}$ & Skor & $\mathrm{f}$ & Skor & $\mathrm{f}$ & Skor & & & \\
\hline 1 & Item 1 & 50 & 250 & 39 & 156 & 10 & 30 & 1 & 2 & 0 & 0 & 100 & 438 & $\begin{array}{l}\text { Sangat } \\
\text { Setuju } \\
\text { Sangat }\end{array}$ \\
\hline 2 & Item 2 & 56 & 280 & 35 & 140 & 8 & 24 & 1 & 2 & 0 & 0 & 100 & 446 & $\begin{array}{l}\text { Setuju } \\
\text { Sangat }\end{array}$ \\
\hline 3 & Item 3 & 54 & 270 & 32 & 128 & 12 & 36 & 1 & 2 & 1 & 1 & 100 & 437 & $\begin{array}{l}\text { Setuju } \\
\text { Sangat }\end{array}$ \\
\hline 4 & Item 4 & 55 & 275 & 35 & 140 & 9 & 27 & 0 & 0 & 1 & 1 & 100 & 443 & Setuju \\
\hline \multicolumn{12}{|c|}{ Skor Nilai Variabel Persepsi Keamanan } & & 1764 & \\
\hline $\begin{array}{l}\text { Rat } \\
\text { Pers }\end{array}$ & $\begin{array}{l}\text {-Rata Variab } \\
\text { entase }\end{array}$ & el Per & sepsi & eam & anan & & & & & & & & $\begin{array}{l}441 \\
88.2\end{array}$ & $\begin{array}{l}\text { Sangat } \\
\text { Setuju }\end{array}$ \\
\hline
\end{tabular}

Sumber : data diolah, 2020 